\title{
Reflexões Acerca \\ de Compreensões de Currículo \\ de Professores em Exercício
}

\author{
Indman Ruana Lima Queiroz ${ }^{1}$ \\ Elisa Prestes Massena ${ }^{2}$
}

\begin{abstract}
Resumo
Este trabalho apresenta compreensões de currículo de professores em exercício de escolas públicas da Região Nordeste do país. 0 objetivo é fornecer elementos para se (re)pensar as discussões de currículo em cursos de formação inicial. Os sujeitos da pesquisa foram dez professores de duas cidades nordestinas que responderam a um questionário misto e participaram de uma entrevista semiestruturada. Os resultados mostraram que as compreensões de currículo de muitos professores ainda estão ancoradas nos conteúdos propostos pelo livro didático e também pelo que é exigido nos exames de acesso ao ensino superior. Esses aspectos podem ser consequência de como as discussões de currículo ocorrem nos cursos de formação inicial de professores e indicam a necessidade da formação continuada desses sujeitos.
\end{abstract}

Palavras-chave: Currículo. Formação de professores. Ensino de Química.

\section{REFLECTIONS ON TEACHER CURRICULUM UNDERSTANDING ON EXERCISE}

\begin{abstract}
This paper presents teachers curriculum understandings in exercise of public schools the Northeast region of the country. The objective is to provide information to (re)think the resume discussions on initial education courses. Research subjects were ten teachers in two cities northeastern who responded to a mixed questionnaire and participated in a semi-structured interview. The results showed that many teachers curriculum understandings are still anchored in the proposed content for the textbook and also what is required in entrance examinations to higher education. These aspects may be the result of how the curriculum discussions take place in the initial training courses and indicate the need for continued education of these teachers.
\end{abstract}

Keywords: Curriculum. Teacher education. Teaching of Chemistry.

${ }^{1}$ Licenciada em Química (Uesc); mestre em Educação em Ciências (Uesc); doutoranda do PPG em Ensino, Filosofia e História das Ciências (UfbalUefs). indmam_ruana@hotmail.com

2 Licenciada em Química (UFRJ); doutora em Educação (UFRJ) - Departamento Ciências Exatas e Tecnológicas; Área: Ensino de Química. elisapmassena@gmail.com 


\section{Situando o Tema em Questão}

As compreensões de currículo de professores de Química do Ensino Médio possibilitam reflexões acerca de como se deram as discussões desse tema na formação inicial. Isto porque a apropriação de quais conteúdos ensinar, como ensinar e porque ensinar influenciará os sujeitos a serem formados. Por outro lado, a ausência dessas discussões na formação inicial de professores poderá propiciar uma menor reflexão crítica sobre os conteúdos a serem ministrados quando os sujeitos se tornarem professores.

As questões de currículo não estão relacionadas somente aos conteúdos, mas é importante ressaltar que, em alguns processos de avaliação em massa, este aspecto é explicitado. Como exemplos, podemos citar o Exame Nacional do Ensino Médio (Enem), o Sistema de Avaliação da Educação Básica (Saeb) e o Programme for International Student Assessment (Pisa), que apresentam como objetivo diagnosticar o que os alunos aprendem nas escolas. Em relação aos anos 2000, estas avaliações apontaram resultados insatisfatórios e demonstraram o baixo desempenho dos alunos brasileiros, principalmente na área de Ciências e Matemática, o que nos leva a pensar nas implicações que o currículo apresenta em sala de aula (Maia; Justi, 2008; Waiselfisz, 2009; Werle, 2011).

Esta questão não é nova. No Brasil, a discussão sobre o currículo da disciplina escolar Química, por exemplo, vem sendo realizada, desde o surgimento desta disciplina em 1930. Com o início desta década já se pensava em um ensino articulado ao cotidiano escolar (Rosa; Tosta, 2005). A partir de 1970, entretanto, se estabeleceu um ensino de Química voltado para a formação de técnicos e, após mudanças no sistema de ingresso nas universidades brasileiras, de modo geral, observou-se no conteúdo do ensino de Química uma influência dos modelos utilizados nos cursos preparatórios e pré-vestibulares. Em consequência disso, "um significativo número de livros didáticos derivou das apostilas de cursinho, tendo como características básicas a exposição sintética dos conteúdos e um grande número de exercícios de vestibulares, com o objetivo de treinar os alunos para resolvê-los" (Brasil, 2011, p. 7). A relação entre os conteúdos dos livros didáticos e o ingresso no nível superior pode influenciar na qualidade do ensino de Química, pois ainda hoje este material é abundantemente utilizado 
pelos professores. Considerando que, em algumas escolas é o principal material didático utilizado na elaboração das aulas, torna-se evidente sua forte influência na prática docente desses profissionais (Maia et al., 2011).

Segundo Echeverría, Melo e Gauche (2010), os professores nem sempre fizeram, durante sua formação inicial, um estudo sobre os livros didáticos, e seu uso indiscriminado aponta para o fato de que, às vezes, o professor não tem clareza da razão que o fez optar por tal livro e tampouco porque ensina determinado conteúdo. Assim, os processos de ensino de Química desses professores, geralmente, apresentam aspectos como a excessiva carga de conteúdos e o uso de fórmulas e "macetes" com fins de memorização que não contribuem para resultados satisfatórios, quando observado o atual objetivo do processo educacional de formação para a cidadania (Santos; Schnetzler, 1996).

Tanto a escolha do livro quanto a seleção dos conteúdos a serem ensinados podem ser entendidos como parte das necessidades formativas dos professores de Química. Segundo Carvalho e Gil-Pérez (2006), existe a necessidade de que o professor saiba preparar atividades capazes de gerar uma aprendizagem efetiva, conheça a matéria a ser ensinada e assim selecionar conteúdos adequados, apresentando uma visão desta Ciência que seja acessível aos alunos e susceptível de interesse, e, dessa forma, seja possível construir um currículo cujo ensino esteja voltado para a formação do cidadão.

Assim, neste trabalho a questão de pesquisa que se coloca é "Como têm ocorrido a apropriação sobre currículo pelo professor em exercício?", sendo importante pontuar que se trata de professores em exercício de duas cidades do Nordeste do Brasil, formados em um curso de Licenciatura em Química específico. Pretendemos responder a essa pergunta tendo como objetivo de pesquisa fornecer elementos para se (re)pensar as discussões de currículo em cursos de formação inicial a partir de compreensões de currículo de professores de Química em exercício.

\section{Com que Lentes Enxergamos?}

No contexto do ensino de Ciências brasileiro, é significativa a discussão em torno das questões curriculares (Bucussi; Ostermann, 2006; Silva; Lopes, 2007; Kato; Kawasaki, 2011), pois um dos desafios da pesquisa educacional é 
a melhoria da qualidade da educação. Dentre os trabalhos mais recentes, Trujilo (2013) investigou qual o critério existente na sequência dos conteúdos dos livros didáticos de Química para justificar um critério alternativo baseado no uso da história e filosofia da ciência. Como resultado, percebeu que deve haver uma articulação entre a história e a filosofia da ciência, assim como de outros campos do conhecimento, na busca de um ensino que administre e desfrute do conhecimento histórico e filosófico sobre a química.

Cerqueira e Santos (2013) buscaram compreender as articulações que ocorrem no cotidiano escolar durante a realização de uma proposta de inovação no currículo de Química. Este estudo mostrou que a inovação curricular é capaz de ampliar os espaços e as possibilidades para o ensino de Química em sua articulação com o cotidiano escolar. Nesse ínterim, "a busca por um currículo inovador para o ensino de Química, e até mesmo para outras disciplinas, envolve, além de uma compreensão sobre a dinâmica das relações dos espaços/lugares na escola, um entendimento da força política capaz de legitimá-la" (Cerqueira; Santos, 2013, p. 7).

Uma dificuldade para a realização de propostas de inovação curricular é a falta de entendimento dos próprios licenciandos sobre como relacionar os conteúdos aprendidos ao cotidiano. Os conhecimentos aprendidos na formação inicial muitas vezes não se relacionam com a vida cotidiana dos próprios licenciandos. Sgarbi (2007, p. 25) ressalta que "não é que os conhecimentos curriculares da formação específica não sirvam a uma prática docente, mas sim que os próprios graduandos não são levados a compreender como esses conhecimentos acontecem no cotidiano das pessoas". Ou seja, entendemos que deve haver semelhanças entre a formação recebida nos cursos de licenciatura e a prática que se pede que este futuro profissional pratique, tendo em vista que o professor terá mais facilidade de atuar quando aquilo que acontece em sua prática reflete as experiências vivenciadas durante sua formação.

Outros autores como Sangiogo et al. (2011), afirmam que uma das alternativas dessa aproximação é inserir a pesquisa como componente curricular na formação de professores de Química. Para eles, essa inserção pode minimizar as marcas da visão tecnicista que ainda estão presentes em alguns professores. 
Além disso, defendem que a realização da pesquisa educacional como atividade curricular pode potencializar a formação do professor também como pesquisador de sua prática. Os autores mostraram que a atividade de pesquisa propicia ao licenciando o

contato com professores e alunos de escolas, identificação e análise de livros didáticos, exercício da escrita com base em argumentos, capacidade de elaboração de perguntas adequadas para avaliações de resultados do processo de ensino e aprendizagem, entre outros (Sangiogo et al., 2011, p. 537).

Ainda para os autores supracitados, essa prática contribui para que o licenciando não se enxergue apenas como "consumidor" da pesquisa educacional, mas como pesquisador de sua própria prática.

Costa-Beber e Maldaner (2011) investigaram a ênfase da contextualização em dois trabalhos publicados na década de 90, que descrevem propostas curriculares de educação em Química com foco no cotidiano. Os conceitos de contextualização apresentados em ambos os trabalhos foram semelhantes. Em meio a outras inferências, os pesquisadores constataram que os novos achados sobre práticas pedagógicas não devem desconsiderar propostas de reconfiguração curricular anteriores, que muito têm a contribuir às novas reconfigurações.

Outra alternativa para a aproximação de semelhanças entre as práticas dos professores formadores e dos professores da Educação Básica pode ser a utilização da Situação de Estudo em situações de sala de aula de professores da escola. A Situação de Estudo é uma proposta que possibilita a discussão dos pressupostos teóricos e práticos necessários para a reconstrução curricular. Nela, a seleção e organização dos conteúdos a serem estudados estão relacionadas a uma temática, ou seja, uma situação real que, de alguma forma, se faz presente no contexto dos alunos (Maldaner; Costa-Beber; Machado, 2012).

Na literatura também são encontrados textos voltados para a perspectiva da construção de um currículo que relacione os conteúdos às experiências de vida dos educandos (Muenchen; Auler, 2007; Halmenschlager; Stuani; Souza, 2011; Boff; Rosin; Del Pino, 2012). Analisando como professores do Ensino Médio se apropriam de um discurso de inovação curricular de Química para este 
nível da educação, Leal e Mortimer (2008) puderam observar a complexidade do processo de recontextualização do discurso de inovação curricular. Essa constatação mostra a necessidade de mais investigações sobre essa temática, para que os professores da Educação Básica tenham acesso aos resultados e possam refletir na busca da melhoria de sua prática docente. Pode ser importante, ainda, a realização de pesquisas que reflitam sobre a autonomia do professor. Nesse sentido, Marcondes e Moraes (2013) relacionaram a temática da pesquisa ao currículo. Estes autores constataram que o sistema apostilado de algumas redes de ensino não tem contribuído para a autonomia docente de construção curricular.

Em nossa revisão foram identificadas diferentes bases teóricas que podem ser adotadas para um diálogo sobre o currículo. Por isso, se faz necessário expor qual compreensão adotaremos, ou seja, com quem dialogaremos ao discutir sobre currículo. Segundo o dicionário Houaiss (2011), "currículo" significa aquele que conduz, que orienta, que dá indicações práticas sobre algo. Conforme Sacristán e Gómez (1998, p. 125), "o termo currículo provém da palavra latina currere, referente à carreira, a um percurso que deve ser realizado". Desta forma, a etimologia da palavra currículo nos sugere que a escolaridade é um percurso para os alunos e o currículo é o guia desse processo. Assim como Goodson (2005, p. 83), entendemos que "o currículo é confessada e manifestadamente uma construção social". Ou seja, há um percurso a ser realizado, contudo esse percurso é determinado pelos sujeitos sociais, o que implica que suas marcas poderão interferir no currículo. Isso traz a ideia de um currículo em fluxo contínuo e em transformação. Desta forma, os conhecimentos que compõem o currículo em determinado momento e em uma determinada sociedade podem não ser considerados como os mais importantes em outro contexto. O currículo, portanto, não é constituído de conhecimentos válidos, mas de conhecimentos que são validados socialmente. Considerando a influência que os sujeitos sociais exercem sobre a construção do currículo, podemos afirmar que o currículo não é neutro.

Para que o currículo de Química do Ensino Médio seja tratado dessa forma, se faz necessário que o professor saiba transformar o conhecimento químico acadêmico em conhecimento escolar. Segundo Lopes (2005, p. 265), alguns princípios configuram o entendimento de que disciplinas escolares são 
diferentes de disciplinas científicas e acadêmicas. De acordo com esses princípios, a disciplina escolar é “1) uma construção sócio-histórica; 2) uma tecnologia de organização curricular; 3) um produto da recontextualização de discursos; e 4) um híbrido de discursos curriculares". Entendemos que o papel da formação inicial é fazer com que isso fique claro para o futuro professor.

Segundo Marcelo Garcia (1999), a formação de professores deve ser concebida como o ensino que profissionaliza para a docência. Assim, tem a função de transmitir um saber fazer e um saber ser, de promover o desenvolvimento e a estruturação da pessoa como professor, e de organizar esses processos de modo formal. Para o mesmo autor, uma das peculiaridades da formação de professores é o fato de ser uma "formação de formadores", ou seja, nela forma-se professores que irão atuar na formação básica de outros indivíduos. Deste modo, estes professores são marcados por suas vivências que provavelmente influenciarão em sua prática docente. Grande parte dos professores, todavia, exercem suas atividades participando de processos de elaboração e aplicação de currículos sem ter tido em sua formação a oportunidade de conhecer e analisar o que vem sendo pensado, investigado e construído a respeito do currículo (Moreira, 1999). Este fato acaba gerando uma seleção dos conteúdos a serem ministrados no Ensino Médio que pouco contribui para uma formação plena dos estudantes.

\section{O Percurso Metodológico}

A pesquisa em questão é de cunho qualitativo (Bogdan; Biklen, 1994; Günther, 2006). Nela, buscamos responder a questão já apresentada "Como têm ocorrido a apropriação sobre currículo pelo professor em exercício?" mediante as compreensões sobre currículo de dez professores de Química em exercício em escolas públicas da Educação Básica de duas cidades do Nordeste do Brasil. É importante ressaltar que a quase totalidade dos professores em exercício desta pesquisa foram formados pela única instituição que à época oferecia o curso de Licenciatura em Química, ademais, esses professores também atuam como supervisores na coformação dos licenciandos junto as disciplinas de Estágio Supervisionado. 
Foram utilizados como instrumentos de coleta de dados um questionário misto, respondido por dez indivíduos, e uma entrevista semiestruturada, respondida por quatro dos sujeitos que responderam ao questionário (Minayo; Assis; Souza, 2005). A fim de preservar sua identidade, os nomes utilizados para os professores são fictícios. O questionário misto, com dez questões, possibilitou uma espécie de diagnóstico dos indivíduos. Nele, as questões inquiriam sobre a formação, o tempo de prática docente, materiais que utilizam para a preparação de aulas, a seleção dos conteúdos a serem trabalhados em aula, e a compreensão sobre currículo dos professores. A entrevista semiestruturada com quatro questões tratava sobre: a forma como os conteúdos são determinados e o porquê dessa forma; como o professor leva em consideração o entorno do aluno no processo de seleção dos conteúdos; como a interferência da experiência docente sobre a seleção de conteúdos acontece; e as relações entre os conteúdos ensinados e a formação do cidadão. A entrevista permitiu o aprofundamento de pontos levantados pelo questionário e deixou os professores à vontade para expor questões que considerassem importantes.

Os dados do questionário e da entrevista foram analisados a partir da Análise Textual Discursiva (ATD), uma metodologia de análise de dados que, de acordo com Moraes e Galiazzi (2013), possibilita um contato intenso com os materiais analisados. O processo da ATD permitiu que todos os dados discursivos obtidos (tanto dos questionários quanto das entrevistas) - o corpus -, fossem desconstruídos, a fim de atingir unidades de significado referentes aos fenômenos estudados. As unidades de significado provenientes dos questionários e das entrevistas são representadas por "Q" e "E" quando apresentados na análise e discussão dos resultados. Em um segundo processo, denominado categorização, foram observadas as relações entre as unidades de significado, combinando-as e classificando-as, no sentido de compreender como esses elementos unitários podem ser reunidos na formação de conjuntos, denominados categorias, quando as informações são comunicadas e validadas. Por fim, proporcionado pelos estágios anteriores, o processo de comunicação possibilitou a emergência de uma compreensão renovada do todo - o metatexto, um texto descritivo e interpretativo apresentado no item subsequente (Moraes; Galiazzi, 2013). 
Nesta pesquisa, os dados são discutidos a partir de três categorias: a) compreensões de currículo; b) critérios adotados na seleção dos conteúdos e c) como pensam a sequência dos conteúdos ministrados. Essas categorias foram criadas segundo o método indutivo, ou seja, foram construídas com base nas informações contidas no corpus, em um processo de comparação constante das unidades de significado, em que se organizam conjuntos de elementos semelhantes, geralmente com base no conhecimento que está implícito ou subtendido, denominadas de categorias emergentes (Moraes; Galiazzi, 2013).

\section{O Olhar dos Professores em Exercício}

Nesta seção apresentamos os resultados da análise, na qual emergiram as categorias: "compreensões de currículo", "critérios adotados na seleção dos conteúdos" e "como pensam a sequência dos conteúdos ministrados". A partir dessas categorias mostramos e discutimos como os professores em exercício estão compreendendo o currículo, o que nos proporcionou a reflexão sobre até que ponto essa compreensão pode ser reflexo de sua formação inicial.

\section{Compreensões de Currículo}

Das compreensões que os sujeitos da pesquisa apontaram sobre currículo, ou seja, o que estes professores entendem por esta temática, qual seu ponto de vista, o seu modo de pensar e agir em relação ao currículo, emergiu a categoria Compreensões de Currículo. Percebemos que entre estes professores existem compreensões divergentes, pois o currículo é apontado tanto numa visão que o considera como o guia do processo de escolaridade, quanto numa visão que valoriza a utilização de um número excessivo de conteúdos, que aqui denominaremos de "conteudista".

Alguns dos professores investigados apresentaram compreensões de currículo como um guia. Entendemos que essa compreensão se aproxima do significado de currículo, por isso presumimos que os sujeitos que responderam por este viés foram influenciados por questões etimológicas da palavra. 
Ora essa compreensão aparece de forma mais direta ao responder o questionário, como na resposta da professora Shirlei:

“Quem diz o rumo a seguir” (Prof ${ }^{a}$ Shirlei - Q).

Ora a resposta aparece de forma menos explícita, como na compreensão da professora Tereza, quando o currículo é apontado como:

"Norteador traçado para orientar as atividades letivas, suas finalidades e objetivos. Não devem ser estanques, podendo ser modificados segundo as necessidades e particularidades de cada turma" (Prof ${ }^{\mathrm{a}}$ Tereza-Q).

Percebemos que estas professoras entendem o currículo como um guia, assim como Sacristán e Gómez (1998, p. 125), que acreditam que "o currículo são os conteúdos, o guia do progresso pela escolaridade", justificando esse entendimento pelo fato de a escola - espaço inserido em um sistema de educação formal, ter a necessidade de ser organizada e servir a interesses sociais que inevitavelmente terão consequências decisivas nos sujeitos formados, portanto, tendem a ser controláveis. Desta forma, o professor deve ser capaz de regular e controlar a distribuição do conhecimento, expressando, assim, o que é e o que não é objeto de ensino e estabelecendo a ordem de sua distribuição. A aproximação da compreensão de currículo como guia também é observada na resposta da professora Carla, e a mesma pensa o currículo como

"Um elenco de conteúdos que contemplam a disciplina, com objetivos que norteiam ou delimitam os assuntos que o aluno deve compreender para desenvolver competências e habilidades que servirão como base para os anos seguintes" (Prof ${ }^{a}$ Carla $\left.-Q\right)$.

Embora estas compreensões de currículo se aproximem do significado de currículo, entendemos que este tipo de compreensão não atinge toda a complexidade da construção curricular, uma vez que não fazem indicação a nenhuma função social e política que o currículo exerce sobre os indivíduos que o praticam. 
Outra compreensão dos sujeitos da pesquisa valoriza os conteúdos excessivamente, denominados nesta investigação de "conteudistas". Geralmente os "conteudistas" compreendem o ensino na forma de transmissão-recepção do conhecimento, e a lista de conteúdos como sinônimo de currículo. Indícios dessa compreensão podem ser observados no discurso do professor Antônio acerca do entendimento que possui sobre o currículo.

"Conjunto de saberes, estratégias e conteúdos que devem ser utilizados na formação do educando” (Prof ${ }^{\mathrm{o}}$ Antônio - Q).

Os sujeitos que apresentam compreensões desse tipo provavelmente percebem a aprendizagem como um processo acabado em si mesmo e o currículo como dado, não vislumbrando a possibilidade de construção, ao longo do processo educativo, que acontece de forma gradativa e conjunta em parceria com aqueles que aprendem e ensinam (Goodson, 2005). Assim, quando o conhecimento é apenas transmitido, aqueles que a ele estão submetidos presumivelmente não conseguem compreender o que está sendo ensinado e relacioná-lo com o seu dia a dia. O conhecimento, portanto, deve ser construído junto ao estudante, proporcionando-lhe laços que permitam relacionar o conteúdo com o mundo em que vive por meio da mediação do outro. Existindo essa adequação ao sujeito que o pratica, o currículo estará em constante alteração.

Ao nos debruçarmos sobre os dados desta pesquisa percebemos uma postura tradicional por parte de alguns sujeitos que apresentam a ideia de que tudo será aprendido se o professor mostrar o conteúdo a partir da simples transmissão-recepção de conhecimentos. Este fato pode ser um reflexo das marcas da formação inicial. Como consequência desse entendimento, possivelmente acreditam que o estudante aprendeu Química quando consegue repetir o conceito que é repassado pelo professor em aula (Sangiogo et al., 2011). Percebemos a existência de professores que utilizam apenas conteúdos para definir o currículo. Tal definição pode ser observada no discurso da professora Camila.

"Conjunto de conteúdos organizados de forma a desenvolver competências e habilidades” (Prof ${ }^{a}$ Camila - Q). 
Essas respostas nos mostram que alguns professores ainda compreendem o currículo somente como um conjunto de conteúdos, sem considerar que este implica também em distribuição de diferentes tipos de conhecimentos para distintos tipos de classes sociais (Goodson, 2005). Uma reconfiguração curricular que abarque essas questões pode ser alcançada utilizando-se a Situação de Estudo, posto que esta forma de currículo relaciona a seleção e organização dos conteúdos à temáticas que façam parte do contexto dos alunos (Maldaner; Costa-Beber; Machado, 2012).

O discurso da professora Mariana, é similar ao dos professores Antônio e Camila.

"Desde os conteúdos até as habilidades e atitudes desenvolvidas no processo de aprendizagem” (Prof ${ }^{a}$ Mariana - Q).

Como percebemos no que destaca a professora Mariana, mais uma vez as questões sociopolíticas relacionadas ao currículo não são citadas, bem como as relações entre estes conteúdos com a resolução de problemas do cotidiano do aluno, ou seja, questões relacionadas ao seu dia a dia.

Considerando Marcelo Garcia (1999), entendemos que estas compreensões refletem as marcas impressas no professor ao longo de sua formação. Levamos em conta, ainda, que a formação do professor sofre influências da sua socialização com a profissão enquanto aluno da formação inicial e da formação continuada. Pensando especificamente na formação inicial, estes professores podem estar refletindo o modo como foram formados. Presumimos que a formação destes professores não tenha deixado explícitas as discussões sobre currículo ou que elas não foram abordadas em uma perspectiva crítica. Nestes casos, o que mais marca o professor é o conceito de currículo. Essas discussões podem também ter sido deixadas em segundo plano. Nesta possiblidade, provavelmente o professor utilizará da sua experiência como aluno, recordando-se de como os seus antigos professores construíam seus currículos. Em nossa compreensão, as discussões sobre currículo não podem ficar implícitas, elas devem estar evi- 
dentes tanto na formação inicial quanto na continuada de professores. Segundo Goodson (2005), é necessário que o professor esteja consciente de que a inclusão ou exclusão de aspectos no currículo tem relação com a sociedade.

\section{Critérios Adotados na Seleção dos Conteúdos}

Nesta investigação foi possível perceber indícios dos critérios de seleção de conteúdos mais utilizados pelos sujeitos investigados. Os indícios mostram que os conteúdos abordados em avaliações e os conhecimentos que se relacionam ao cotidiano do aluno são os critérios mais empregados pelos professores ao compor o seu currículo. Estes critérios trazem implicações distintas à formação do indivíduo. Alguns dos sujeitos investigados destacam que as avaliações, a exemplo de exames de vestibular e do Exame Nacional do Ensino Médio (Enem), considerando-as como o fio condutor da construção curricular, tendo como mais relevantes os conteúdos que elas abordam com mais frequência.

A relação entre currículo e avaliação não é recente; ela acontece desde a criação do conselho examinador das universidades, por volta de 1900. Neste momento, os conteúdos exigidos eram aqueles ensinados às classes sociais superiores. Consequentemente, essas classes eram privilegiadas no ingresso ao ensino superior. Sendo assim, esses exames se constituíam como diferenciadores sociais. O conselho examinador das universidades proporcionou também, mudanças no currículo escolar. Para atender essa demanda, foi criada a matéria escolar, com uma série de horários e de aulas compartimentalizadas, surgindo juntamente com as classes escolares, no momento em que a escolarização em massa passou a ser subsidiada pelo Estado (Goodson, 2005).

Ainda hoje podemos observar indícios da influência histórica do conselho examinador das universidades na prática dos professores, exemplificado pelo que o professor João expõe a seguir sobre quais critérios ele adota na seleção dos conteúdos que ensina.

"Determino a partir da análise do que é pedido nos níveis seguintes, no Enem, nos vestibulares, do que é exigido mais na nossa região” (Prof ${ }^{\circ} \mathrm{João}-\mathrm{E}$ ). 
Assim, o que ocorre na construção curricular de professores com compreensões desse tipo pode ser reflexo de como o currículo vem sendo construído historicamente. Considerando que estes professores atuam em escolas públicas, com alunos de classes desfavorecidas, a preocupação com o ingresso desses estudantes no Ensino Superior pode ser uma forma de incentivo para que eles conquistem uma ascensão social.

Essa inclinação também pode ser observada na fala dos professores Odete e Antônio:

"Começo seguindo a programação do vestibular, ali é digamos assim -o eixo central" [sic] (Prof ${ }^{a}$ Odete $\left.-\mathrm{E}\right)$.

"Adequo os conteúdos de acordo com o que é mais cobrado no Enem e no vestibular, especificadamente aqui da universidade da região" (Prof ${ }^{\circ}$ Antônio - E).

Neste ponto, nossos resultados reforçam os resultados obtidos no trabalho de Maia et al. (2011), que já identificavam, por parte de professores da região, a valorização excessiva em ensinar conteúdos "para o vestibular". Deste modo, essas falas acentuam a existência de uma visão focada nestes processos por profissionais desta região. Além do vestibular, observamos que o Enem também já se fazia presente nos discursos desses professores:

"No caso específico da nossa escola a gente tem uma preocupação com a preparação desse aluno para o vestibular, a gente baseia o trabalho também no Enem mas, a gente foca mesmo no vestibular da universidade da região e é porque os nossos alunos têm acesso" (Prof ${ }^{a}$ Camila - E).

Estes professores citam uma universidade localizada entre duas cidades na região Sul da Bahia por ser a mais próxima das cidades em que residem, portanto, seus alunos tem maior perspectiva de acesso, além de ser a universidade onde a maioria dos professores investigados se formaram; e em relação ao Enem, por este sistema de avaliação estar se constituindo um importante meio para o ingresso em instituições públicas e particulares de ensino superior. Tomar por base apenas as avaliações para a construção do currículo tende, contudo, a 
fazer com que as disciplinas escolares passem a ter características de matérias acadêmicas. Isso acarreta em um ensino com uma carga excessiva de conteúdo e que toma as teorias curriculares como prescrição (Goodson, 2005). Quando falamos em excesso de conteúdo não estamos pensando em desprezá-lo. Estamos falando de uma seleção de conteúdo que valorize a qualidade da aprendizagem, não apenas a quantidade.

Algumas compreensões apontaram para critérios de seleção de conteúdos que giram em torno da relação destes com o cotidiano do aluno, ou seja, como esses conhecimentos acontecem no cotidiano das pessoas. $\mathrm{O}$ ensino, que tem por base o cotidiano do aluno, é aquele que visa a "buscar entender de maneira diferente do aprendido, as atividades do cotidiano escolar ou do cotidiano comum" (Sgarbi, 2007, p. 26). Mesmo que o professor não tenha indicado a importância de se estudar conteúdos ligados ao cotidiano, nesta pesquisa este fato aparece em alguns momentos de suas falas em relação aos seus critérios de seleção de conteúdo.

"Conteúdos que estejam relacionados com o cotidiano e de dados obtidos a partir de perguntas sobre a realidade da vida deles" (Prof ${ }^{\circ}$ Carlos $\left.-\mathrm{Q}\right)$.

"Conteúdos que estejam relacionados com o dia a dia do aluno" (Prof ${ }^{\mathrm{a}}$ Odete - Q).

Discursos como os dos professores Carlos e Odete apresentam indícios de práticas que vão além de técnicas laboratoriais químicas, e que valorizam a Química ensinada a partir do cotidiano dos alunos. Embora para alguns sujeitos esse cotidiano pareça simples, ele gera situações de ensino ricas e complexas que podem ser explicadas a partir dos conceitos científicos. "Nessa perspectiva, é bastante comum a expressão 'A Química está em tudo', confundindo os iniciantes no que se refere ao significado da palavra Química: Química é coisa ou é conhecimento?" (Rosa; Tosta, 2005, p. 257). Existe, portanto, a necessidade de saber o que é preciso ensinar sobre o cotidiano e porque se ensinar por meio de assuntos do cotidiano. Percebemos esse entendimento no que expressam as professoras Odete e Mariana. 
"Procurar dar os assuntos que interessa a eles e ir relacionando toda nossa vida. Quando eu construo meu currículo, eu penso no tipo de aluno que eu vou receber, por isso que muitas vezes eu não sigo a programação que vem de lá para a gente, eu faço minhas adaptações aqui" (Prof ${ }^{\text {a }}$ Odete $\left.-E\right)$.

"Não trabalho muito para o vestibular não, porque a maioria não quer, aqueles que querem têm condições de buscar outros meios, e também você trabalhando o cotidiano eles podem desenvolver também essa questão do vestibular" [sic] (Prof ${ }^{a}$ Mariana - E).

É importante ressaltar que contextualizar a Química não significa promover uma ligação artificial entre o conhecimento e o cotidiano do aluno, citando exemplos ilustrativos após ensinar um conteúdo, mas pode significar a proposição de "situações problemáticas reais e buscar o conhecimento necessário para entendê-las e procurar solucioná-las" (Brasil, 2002, p. 93). Ensinar desta forma é de extrema importância, pois esta metodologia propicia ao aluno uma melhor aprendizagem e lhe possibilita facilidade em transpor o conhecimento escolar para a sua realidade.

Apesar de estes professores apontarem por diversas vezes a questão do cotidiano do aluno, o que implica um ensino contextualizado, não podemos afirmar que os mesmos estão de fato selecionando o conteúdo desta forma. É preciso, entretanto, investigar também o currículo praticado por estes professores para se certificar de que os discursos que exploram o cotidiano do aluno não estão passando de teoria (Goodson, 2005).

De acordo com Marcelo Garcia (1999), consideramos que o currículo da formação inicial também poderia ter por base questões que estabelecessem relações com o cotidiano do professor em formação. Isso porque acreditamos que, apesar de ter objetivos educacionais diferentes, podem existir semelhanças entre o currículo acadêmico e o escolar. Isso contribuiria para que os processos de ensino e aprendizagem de ambos os níveis de formação fossem melhorados. 


\section{Como Pensam a Sequência dos Conteúdos Ministrados}

Por fim, analisamos como os professores pensam a sequência dos conteúdos ministrados em suas aulas, durante este processo observamos duas vertentes. Na primeira predomina o discurso de que o objeto que define a sequência dos conteúdos ministrados são os conteúdos que já foram estudados por estes alunos e os conhecimentos adquiridos em sua experiência de vida, chamado por estes sujeitos de conhecimento prévio. A segunda vertente é aquela em que o objeto que define a sequência dos conteúdos ministrados é o livro didático.

Algumas das falas levam em conta os conhecimentos prévios dos alunos, considerando sua bagagem a partir do convívio com a sociedade e com os conhecimentos formais que lhes foram ensinados nas séries anteriores. É importante que sirvam também como base para a compreensão de novos conhecimentos. O comentário da professora Shirley, descrito a seguir, indica este fato.

"Necessidade do conhecimento, conhecimento já adquirido pelo aluno, nível de complexidade, necessidade do conteúdo para desenvolvimento dos demais" (Prof ${ }^{\mathrm{a}}$ Sheila - Q).

Sabemos que há uma tendência equivocada entre os professores do Ensino Médio de considerar o conhecimento escolar como conhecimento científico adaptado aos alunos. Isso os leva a pensar que é necessário abordar na Educação Básica todo o conhecimento adquirido na universidade. Isso pode acarretar uma compreensão equivocada sobre conhecimento prévio, caso o professor esteja equiparando o currículo escolar acadêmico ao currículo escolar. O professor pode também associar o conhecimento prévio do aluno aos pré-requisitos do currículo de nível superior (Marcelo Garcia, 1999). Desta forma, as ideias dos alunos não são consideradas referência quando estes professores estão selecionando os conteúdos a serem ensinados. Isso indica que as questões sociais, históricas e políticas do currículo não estão sendo levadas em conta (Goodson, 2005). Por conseguinte, a construção curricular destes professores se configura apenas como uma adequação do conhecimento científico ao nível de conhecimento dos alunos. 
No entendimento de Carvalho e Gil-Pérez (2006), se o desejo é promover um ensino como construção de conhecimentos, o interesse no conhecimento prévio dos alunos geralmente é priorizado. Segundo Lopes (2005), o conhecimento científico é diferente do conhecimento escolar, que, por sua vez, deve ser mediado, em um trabalho que o transforma em um objeto de ensino. Para isso, é preciso conhecer o aluno e o seu contexto, como afirma a professora Carla:

"Bom, primeiro eu faço uma avaliação da turma, o quê que eles estudaram no ano passado, o quê que eu posso continuar, o quê que eu posso trazer de novo, como que eu vou construir esse currículo, geralmente eu faço um diagnóstico" (Prof ${ }^{a}$ Carla - E).

Carvalho e Gil-Pérez (2006, p. 43) orientam que sejam elaboradas atividades que gerem uma concepção e um interesse pelo conteúdo, o que implica "considerar as ideias, visão de mundo, destrezas e atitudes que os alunos possam já possuir, de forma a integrá-la com seus interesses (e gerar outros novos), tendo presentes os pré-requisitos para o estudo a realizar”. Essa preocupação com o contexto e em desenvolver o interesse dos alunos é observada nas respostas da professora Camila:

"São conteúdos que serão a nível didático-pedagógico pré-requisitos para a série seguinte, conteúdos que estejam vinculados à realidade local... onde a gente aborda esses conteúdos locais" (Prof ${ }^{a}$ Camila - E).

Analisando esta fala acreditamos que esta professora supostamente avalia o que o seu aluno traz de conhecimento, "sua bagagem", para saber se este possui base suficiente para prosseguir nos estudos de determinados conteúdos. Para a construção de um ensino pautado no conhecimento prévio dos alunos, é necessário romper com visões simplistas sobre o ensino e a aprendizagem de Ciências/Química. É preciso levar em consideração que toda transformação deve se apoiar em uma base teórica de conhecimentos, que exige mais que aquisições pontuais e dispersas. 
Em relação à segunda vertente, encontramos professores que pensam o livro didático como o principal material auxiliar na sequência dos conteúdos ministrados. Alguns deles seguem exclusivamente este material, sem uma análise crítica do que realmente faz sentido para seus alunos. Ao pensarem dessa forma, trazem as ideias de um currículo fixo e igualitário (Goodson, 2005). Isto se diferencia da pesquisa realizada por Maia et al. (2011, p. 120) com professores da mesma região, em que "a maioria dos professores alega recorrer a mais de uma fonte, além do livro didático" para a elaboração de suas aulas. Em seguida pode-se observar a fala da professora Mariana.

"Sigo a sequência do livro didático para não atropelar os conteúdos e para que os alunos não vejam o mesmo conteúdo no $1^{\circ}$ e $2^{\circ}$ ano, por exemplo" (Prof ${ }^{a}$ Mariana -Q).

Este comentário da professora Mariana indica que os professores utilizam o livro didático como um material que respeitam e, provavelmente seguem à risca, sem a reflexão da relevância do conteúdo para os seus alunos. O ensino praticado em muitas escolas, com base em livros tradicionais, não consegue significar as muitas dimensões do conhecimento para torná-lo útil no contexto da vida das pessoas. Percebe-se, contudo, nesta investigação, que a construção curricular pautada no livro é frequente, como apontado pela professora Maria, quando questionada sobre a forma como define a sequência dos conteúdos a serem ensinados e aprendidos.

"Seleciono através do projeto pedagógico da escola, dos assuntos que permeiam a contemporaneidade e, principalmente, da sequência dos livros didáticos" (Prof ${ }^{\mathrm{a}}$ Maria - Q).

Essa forma de construção curricular não é considerada adequada, pois, como se apresenta o conhecimento na maioria dos livros de Química utilizados nas escolas, simplifica-se demasiadamente os conteúdos e "os estudantes acabam apresentando significados conceituais limitados" (Sangiogo et al., 2011, p. 526). O mesmo pode ser visto na fala da professora Tereza, a seguir. 
"Sigo a sequência dos livros didáticos, mudando apenas alguns conteúdos de acordo com a necessidade da turma" (Prof a Tereza - Q).

Esta fala assinala que alguns professores compreendem o livro didático como uma receita de como ensinar, e seguem basicamente o que é proposto, sem perceber se aqueles conteúdos são adequados para serem ensinados no contexto em que estão inseridos, fazendo com que se perca até mesmo o sentido de se aprender Química. O uso exclusivo do livro didático tende a padronizar o ensino. Para Goodson (2005), o currículo deve considerar as questões sociais, pois um padrão não proporcionará um ensino eficaz, uma vez que não atenderá às demandas de públicos determinados, com características sociais distintas.

Com base em Marcelo Garcia (1999), entendemos que uma possibilidade para o incentivo à prática curricular autônoma é a promoção de propostas de inovação curricular por parte das instituições formadoras. Isso porque a formação de professores deve ser entendida como facilitadora da melhoria do ensino. Outra possibilidade seria a participação dos professores em projetos de formação continuada, pois essa formação pode proporcionar a problematização dos contextos da sala de aula, o diálogo e a possibilidade de modificação de práticas docentes (Rodrigues; Kruger; Soares, 2010).

\section{Considerações Finais}

A partir das categorias "compreensões de currículo", "critérios adotados na seleção dos conteúdos" e "como pensam a sequência dos conteúdos ministrados", presumimos o que os sujeitos investigados têm feito em sua prática. Um exemplo seria a utilização do livro didático como principal instrumento para definir os conteúdos que compõem o currículo. $\mathrm{O}$ fato de a maioria desses professores ser formado pela mesma instituição, nos permitiu perceber algumas possíveis lacunas desta formação inicial, em específico. Uma delas seria a necessidade de que as discussões sobre currículo fossem realizadas de forma mais explícita e crítica, a fim de melhorar a apropriação dos futuros professores ao assunto. Esta apropriação possibilitaria uma visão de currículo mais ampliada, bem como pensar melhorias no currículo da Educação Básica. 
Diante dos resultados apresentados e discutidos observamos que o entendimento de currículo de professores de Química em exercício que atuam nessa região do Brasil se apresenta em torno de duas perspectivas. Uma delas é compreender o currículo como um guia, perspectiva que nos parece não atingir toda a complexidade que a construção curricular possui. A segunda é o entendimento "conteudista", ou seja, que o currículo deve abordar o maior número de conteúdos, sem necessariamente considerar a aprendizagem. Essa prática é decorrente de um vínculo muito forte com os livros didáticos e as avaliações.

As avaliações surgem no discurso desses professores quando questionados sobre os critérios adotados na seleção dos conteúdos a serem ensinados. Esse critério de seleção de conteúdo muitas vezes está associado a aulas expositivas, que não levam à compreensão do conteúdo, apenas a sua memorização para reprodução. Outro aspecto citado como parâmetro para selecionar os conteúdos diz respeito ao cotidiano do aluno. Segundo alguns desses sujeitos, os conhecimentos científicos ensinados a partir do dia a dia do aluno são considerados por fazer mais sentido e melhorar a aprendizagem.

Em relação à forma com que os professores estabelecem a sequência dos conteúdos ministrados, temos indícios de que os conhecimentos prévios dos alunos e a utilização do livro didático são as formas mais utilizadas. Quanto aos conhecimentos prévios, se considerados apenas como os conhecimentos escolares ensinados nos anos anteriores, provavelmente não contribuirão para a construção de um currículo em conjunto com os alunos. Se, entretanto, os professores compreenderem que, além dos conteúdos, os conhecimentos prévios adquiridos de modo informal na vida dos alunos também podem trazer contribuições importantes, o currículo provavelmente contribuirá de forma mais efetiva na formação do cidadão.

Percebemos que o uso do livro didático pode estar determinando a sequência dos conteúdos ensinados pelos professores. Além disso, foi observado que esse material didático estabelece relações com aqueles sujeitos que compreendem o currículo na visão "conteudista". Geralmente há uma volumosa 
quantidade de conteúdos abordados nos livros didáticos e os professores que utilizam este material, muitas vezes, pretendem esgotá-los durante o ano letivo, sem considerar a capacidade de aprendizagem dos estudantes.

As discussões aqui explanadas foram capazes de nos fornecer indícios sobre como os professores em exercício compreendem o currículo e os critérios adotados na seleção e sequência dos conteúdos ministrados. Esses são elementos que nos permitiram (re)pensar as discussões de currículo em cursos de formação inicial de professores de Química. Entendemos que estes cursos devem propiciar mais espaços que discutam sobre currículo, tanto em perspectiva teórica quanto prática, para que os professores em exercício sejam capazes de se posicionar de maneira crítica e considerar seu posicionamento nas situações práticas.

Considerando os sujeitos em questão, é importante pensar a formação continuada desses professores a fim de minimizar entendimentos de currículo "conteudistas", determinados por avaliações e organizados de acordo com livros didáticos ditos tradicionais. Acreditamos que uma visão mais ampliada e crítica de currículo por estes sujeitos contribuirá para a formação de cidadãos que serão capazes de relacionar o conteúdo químico com a sua realidade e intervir sobre ela (Rosa; Schnetzler, 2003; Silva; Bastos, 2012).

\section{Referências}

BRASIL. Guia de Livros Didáticos - PNLD 2012: Química. Brasília: Ministério da Educação, Secretaria de Educação Básica, 2011. 52p. Disponível em: <http://portal.mec. gov.br/index.php?option=com_content\&view=article\&id=12389:guias-do-livro-didatic o\&catid=318:pnld\&Itemid=1129>. Acesso em: 20 mar. 2015.

BRASIL. Orientações Educacionais Complementares aos Parâmetros Curriculares Nacionais-Química, 2002. p. 87-110. Disponível em: <http://www.fisica.ufmg.br/ menfis/ programa/CienciasNatureza+.pdf>. Acesso em: 8 jan. 2014.

BOFF, E. T. O.; ROSIN, C. K.; DEL PINO, J. C. Situação de Estudo. Contexto \& Educação, ano 27, n. 87, p. 166-185, jan./jun. 2012. Disponível em: <https://www.lume.ufrgs. br/bitstream/handle/10183/83623/000903420.pdf?sequence=1>. Acesso em: 25 set. 2015.

BOGDAN, R. C.; BIKLEN, S. K. Investigação qualitativa em educação. Tradução M. J. Alvarez, S. B. Santos e T. M. Baptista. Rev. A. B. Vasco. Portugal: Porto, 1994. 
BUCUSSI, A. A.; OSTERMANN, F. Projetos curriculares interdisciplinares e a temática da energia. Experiências em Ensino de Ciências, v. 1, n. 1, p. 1-13, 2006. Disponível em: <http://if.ufmt.br/eenci/artigos/Artigo_ID14/pdf/2006_1_1_14.pdf>. Acesso em: 10 maio 2014.

CARVALHO, A. M. P.; GIL-PÉREZ, D. Formação de professores de ciências: tendências e inovações. 6. ed. São Paulo: Cortez, 2006.

CERQUEIRA, S. S.; SANTOS, B. F. O lugar do ensino de química em uma experiência curricular inovadora: redes tecidas no cotidiano de uma escola pública. In: ABRAPEC; ENCONTRO NACIONAL DE PESQUISA EM EDUCAÇÃO EM CIÊNCIAS - ENPEC, 9., 2013, Águas de Lindoia. Anais... Águas de Lindoia, 2013. Disponível em: <http:// www.nutes.ufrj.br/abrapec/ixenpec/atas/resumos/R0691-1.pdf>. Acesso em: 20 set. 2015.

COSTA-BEBER, L. B.; MALDANER, O, A. Cotidiano e contextualização na educação química: discursos diferentes, significados próximos. In: ABRAPEC; ENCONTRO NACIONAL DE PESQUISA EM EDUCAÇÃO EM CIÊNCIAS - ENPEC, 8., 2011, Campinas. Anais... Campinas, 2011. Disponível em: <http://www.nutes.ufrj.br/abrapec/ viiienpec/resumos/R1376-1.html>. Acesso em: 15 set. 2015.

ECHEVERRÍA, A. R.; MELO, I. C.; GAUCHE, R. Livro didático análise e utilização no ensino de Química. In: SANTOS, W. L. P.; MALDANER, O. A. (Orgs.). Ensino de química em foco. Ijuí: Ed. Unijuí, 2010. p. 263-286.

GOODSON, I. F. Currículo: teoria e história. Tradução Attílio Brunetta. 7. ed. Petrópolis, RJ: Vozes, 2005. 140p.

GÜNTHER, H. Pesquisa qualitativa versus pesquisa quantitativa: esta é a questão? Psic.: Teor. e Pesq., Brasília, v. 22, n. 2, p. 201-210, maio/ago. 2006. Disponível em: <http:// www.scielo.br/pdf/ptp/v22n2/a10v22n2>. Acesso em: 12 mar. 2015.

HALMENSCHLAGER, K. R.; STUANI, G. M.; SOUZA, C. A. Formação docente no contexto escolar: contribuições da reconstrução curricular via abordagem temática. Alexandria Revista de Educação em Ciência e Tecnologia, v. 4, n. 2, p. 83-107, nov. 2011.Disponível em: <http://alexandria.ppgect.ufsc.br/files/2012/03/Karine.pdf> Acesso em: 17 fev. 2014.

HOUAISS, A. Dicionário Houaiss conciso. Rio de Janeiro: Ed. Moderna, 2011.

KATO, D. S.; KAWASAKI, C. S. As concepções de contextualização do ensino em documentos curriculares oficiais e de professores de Ciências. Ciência \&Educação. v. 17, n. 1, p. 35-50, 2011. Disponível em: <http://www.scielo.br/pdf/ciedu/v17n1/03.pdf>. Acesso em: 25 mar. 2014.

LEAL, M. C.; MORTIMER, E. F. Apropriação do discurso de inovação curricular em Química por professores do Ensino Médio. Ciência \& Educação, v. 14, n. 2, p. 213-231, 2008. Disponível em: <http://www.scielo.br/pdf/ciedu/v14n2/a03v14n2>. Acesso em: 15 jun. 2014. 
LOPES, A. C. Discursos curriculares na disciplina escolar Química. Ciência \& Educação, v. 11, n. 2, p. 263-278, 2005. Disponível em: <http://www.scielo.br/scielo. php?script=sci_pdf\&pid=S1516-73132005000200009\&lng=pt\&nrm=iso\&tlng=pt $>$. Acesso em: 10 jun. 2014.

MAIA, P. F.; JUSTI, R. Desenvolvimento de habilidades no ensino de ciências e o processo de avaliação: análise de coerência. Ciência \& Educação, v. 14, n. 3, p. 431-450, 2008. Disponível em: <http://www.scielo.br/pdf/ciedu/v14n3/a05v14n3.pdf>. Acesso em: 18 jan. 2014.

MAIA, J. O. et al. O livro didático de química nas concepções de professores do Ensino Médio da Região Sul da Bahia. Química Nova na Escola, v. 33, n. 2, p. 115-124, maio 2011. Disponível em: <http://qnesc.sbq.org.br/online/qnesc33_2/07-PE7110.pdf>. Acesso em: 10 jan. 2014.

MALDANER, O. A.; COSTA-BEBER, L. B.; MACHADO, A. R. Desenvolvimento e aprendizagem de conceitos biofisicoquímicos em uma situação de estudo. Alexandria, Revista de Educação em Ciência e Tecnologia, v. 5, n. 1, p. 85-111, maio 2012. Disponível em: <http://alexandria.ppgect.ufsc.br/files/2012/05/Otavio.pdf>. Acesso em: 21 fev. 2014.

MARCELO GARCIA, C. Formação de professores - para uma mudança educativa. Portugal: Porto Editora, 1999. p. 271. (Coleção Ciências da Educação Século XXI).

MARCONDES, M. I.; MORAES, C. L. Currículo e autonomia docente. Currículo sem Fronteira, v. 13, n. 3, p. 461-463, set./dez. 2013. Disponível em: <http://www.curriculosemfronteiras.org/vol13iss3articles/marcondes-moraes.pdf>. Acesso em: 27 abr. 2014.

MINAYO, M. C. de S.; ASSIS, S. G. de; SOUZA, E. R. de. Avaliação por triangulação de métodos: abordagem de programas sociais. Rio de Janeiro: Fiocruz, 2005.

MORAES, R.; GALIAZZI, M. do C. Análise textual discursiva. Ijuí: Ed. Unijuí, 2. ed. 2013. 223p.

MOREIRA, A. F. B. Reflexões sobre currículo de Química. Química Nova na Escola, n. 9, p. 23-27, maio 1999. Disponível em: <http://qnesc.sbq.org.br/online/qnesc09/espaco. pdf>. Acesso em: 15 fev. 2014.

MUENCHEN, C.; D. AULER. Configurações curriculares mediante o enfoque CTS: desafios a serem enfrentados na educação de jovens e adultos. Ciência \& Educação, v. 13, n. 3, p. 421-434, 2007. Disponível em: <http://www2.fc.unesp.br/cienciaeeducacao/ viewarticle.php?id=481>. Acesso em: 14 jul. 2014.

PÉREZ, R. J.; AGUADO, A. M. W. ¿Es posible el cambio en los modelos didáticos personales? Obstáculos en profesores de Ciências Naturales de Educación Secundária. Revista Interuniversitaria de Formación del Profesorado, v. 17, n. 1, p. 113-131, 2003.

RODRIGUES, C. G.; KRUGER, V.; SOARES, A. C. Uma hipótese curricular para a formação continuada de professores de ciências e de matemática. Ciência \& Educação, v. 16, n. 2, p. 415-426, 2010. Disponível em: <http://www.scielo.br/pdf/ciedu/v16n2/ v16n2a10.pdf>. Acesso em: 18 abr. 2014. 
ROSA, M. I. F. P. S; SCHNETZLER, R. P. A investigação-ação na formação continuada de professores de Ciências. Ciência \& Educação, v. 9, n. 1, p. 27-39, 2003. Disponível em: <http://www.scielo.br/pdf/ciedu/v9n1/03.pdf>. Acesso em: 12 maio 2014.

ROSA, M. I. P.; TOSTA, A. H. O lugar da Química na escola: movimentos constitutivos da disciplina no cotidiano escolar. Ciência \& Educação, v. 11, n. 2, p. 253-262, 2005. Disponível em: <http://www.scielo.br/pdf/ciedu/v11n2/07.pdf>. Acesso em: 26 jul. 2014.

SANTOS, W. L. P.; SCHNETZLER, R. P. Função Social. Química Nova na Escola, n. 4, nov. 1996. Disponível em: <http://qnesc.sbq.org.br/online/qnesc04/pesquisa.pdf>. Acesso em: 16 set. 2015.

SACRISTÁN, J. G.; GÓMEZ, P. Compreender e transformar o ensino. 4. ed. Porto Alegre: Artmed, 1998.

SANGIOGO, F. A. et al. A pesquisa educacional como atividade curricular na formação de licenciandos de Química. Ciência \& Educação, v. 17, n. 3, p. 523-540, 2011. Disponível em: <http://www.scielo.br/pdf/ciedu/v17n3/a02v17n3.pdf>. Acesso em: 4 dez. 2014.

SGARBI, P. Avaliação do currículo no cotidiano. Currículo sem Fronteira, v. 7, n. 2, p. 21-37, jul./dez. 2007.Disponível em: <http://www.curriculosemfronteiras.org/vol7iss2articles/sgarbi.pdf>. Acesso em: 12 jul. 2014.

SILVA, V. F.; BASTOS, F. Formação de Professores de Ciências. Alexandria, Revista de Educação em Ciência e Tecnologia, v. 5, n. 2, p. 150-188, set. 2012. Disponível em: <http://alexandria.ppgect.ufsc.br/files/2012/09/vania.pdf>. Acesso em: 8 jun. 2014.

SILVA, D. B. R.; LOPES, A. R. C. Competências nas políticas de currículo. Revista Brasileira de Pesquisa em Educação em Ciências, v. 7, n. 1, 2007. Disponível em: <http:// revistas.if.usp.br/rbpec/article/view/71/64>. Acesso em: 2 dez. 2014.

TRUJILO, C. H. Z. El criterio lógico tras la secuenciación de contenidos en los libros de texto de química: dificultades y consideraciones. In: ABRAPEC; ENCONTRO NACIONAL DE PESQUISA EM EDUCAÇÃO EM CIÊNCIAS - ENPEC, 9., 2013, Águas de Lindoia. Anais... Águas de Lindoia, 2013. Disponível em: <http://www.nutes.ufrj.br/ abrapec/ixenpec/atas/resumos/R1311-1.pdf>. Acesso em: 20 jun. 2014.

WERLE, F. O. C. Políticas de avaliação em larga escala na educação básica: do controle de resultados à intervenção nos processos de operacionalização do ensino. Ensaio: aval. Pol. Públ. Educ., Rio de Janeiro, v. 19, n. 73, p. 769-792, out./dez. 2011. Disponível em: <http://www.scielo.br/pdf/ensaio/v19n73/03.pdf>. Acesso em: 18 mar. 2015.

WAISELFISZ, J. J. O ensino das ciências no Brasil e o Pisa. 1. ed. São Paulo: Ed. Sangari do Brasil, 2009.Disponível em: <http://www.mapadaviolencia.org.br/publicacoes/Pisa. pdf> . Acesso em: 20 mar. 2015.

Recebido em: 12/1/2016

Aceito em: 1\%/2016 